\title{
(AUTO)BIOGRAFIAS, FOTOGRAFIAS, ACERVOS E ESCRITAS DE FORMAÇÃO
}

\section{Apresentação}

Os estudos (auto)biográficos, inicialmente circunscritos aos textos narrativos e a suas potencialidades, nas últimas décadas, têm encontrado outras fontes e múltiplas possibilidades de pensar e problematizar os espaços biográficos e sua expansão. Num movimento muito semelhante ao ocorrido em outros campos epistemológicos, o amadurecimento do campo da pesquisa (auto)biográfica começa a se evidenciar, pela diversificação de interesses e abordagens, e pela sofisticação de sua produção, para além de seu universo inicial, das letras e da história (e, por consequência, dos textos narrativos), e da educação (e, portanto, da entrevista narrativa). As possibilidades abertas para a pesquisa e a compreensão dos mundos da vida humana são múltiplas e o dossiê (Auto)biografias, fotografias, acervos e escritas de formação procura dar materialidade a três dessas perspectivas.

A ideia de se pensar a (auto)biografia a partir da fotografia, como extrato de um momento vivido, como um retrato instantâneo de um acontecimento, no qual a memória ganha uma materialidade - até mesmo, na efêmera fotografia digital - e indaga quem a observa com signos e símbolos de um tempo passado, impressos nas vestimentas, nos comportamentos, nas expressões, nos gestos que sedimentam algo da psicologia ou da mentalidade de um tempo, nos dá algum indício de como estas fontes podem significar alguma diferença nas pretensões de nosso campo de estudo. São um passo rumo a uma outra dimensão representacional.

Essas representações - que, agora digitais, permitem a edição da memória, num exercício cuasi-stalinista de seleção de um passado e até da invenção de uma outra existência - são uma tentativa de enquadrar um instante. Tal como um esboço mais ou menos acabado, a fotografia expressa nossas limitações e habilidades com essa forma de expressão artística. Nas palavras de Cartier-Bresson, "a câmera fotográfica é para mim um caderno de esboços, o instrumento da intuição e da espontaneidade, o soberano do instante que, em termos visuais, ao mesmo tempo questiona e decide. Para significar o mundo, temos que nos sentir implicados no que recortamos através do visor". A fotografia nos dá a possibilidade de uma permanência-simulacro na qual o esboço do que somos pode estar aqui, ali, e na internet, em todos os lugares e não-lugares possivieis.

Outro termo que intitula este dossiê é a noção de acervo, que nos indica, mais que o de fotografia, a capacidade de censura, separação, seleção, apagamento, silenciamento e negação dos objetos que não passam pelo escrutínio de um curador - ou censor - do arquivo. E, por isso, de um acesso a um passado contingenciado pelo que um acervo nos permite entrever. Arquivar, este mal que apaga o inconveniente, o desvio, a transgressão, produz um "ali", onde as coisas habitam, mas também um "ali", onde há um comando, uma ordem, um desejo de controle. ${ }^{2}$ Adentrar um acervo não é adentrar uma compilação, uma coleção, mas um espaço de sentidos e silên-

1 CARTIER-BRESSON, H. O imaginário como ele é. In: CARTIER-BRESSON, H. Henri Cartier-Bresson. Tradução de Jean Clair. São Paulo: Cosac \& Naify, 2011. p. 12. 2 DERRIDA, J. Mal de arquivo: uma impressão freudiana. Tradução de Cláudia Moraes Rego. Rio de Janeiro: Relume-Dumará, 2001. 
cios, de intrigas e interrupções, do visivel e do invisivel, no qual se perguntar pelo que não foi arquivado é tão importante quanto o que é encontrado e catalogado nesse lugar.

Os acervos escondem uma história narrada ou murmurada em primeira pessoa, e sempre sugerem uma perspectiva, uma disposição e uma projeção imaginária. Mantêm em segredo um sentido oculto até o momento de ser revelado pelo observador curioso, que, perseguindo os objetos dispostos, também reconfigura a ordem em sua multiplicidade e universos de sentido. Os acervos que fabricamos nos dão indícios de um passado prefigurado, de acontecimentos instantâneos, mínimos, íntimos, realocados em um conjunto que the conferem outros sentidos. Por isso, os objetos dispostos num acervo são uma reserva de memória material, uma reserva do que fomos e do que poderíamos ter sido.

Nós, os seres humanos, nos relacionamos com as coisas, deixamos marcas de nossas vivências por onde passamos, e essas marcas nos dizem algo também de um passado afetivo, de uma existência deixada nos vestígios de como nos relacionamos com os objetos e, através destes, com os sujeitos no passado. Apesar de a crítica materialista ver nessa relação a expressão de um fetiche, e produzir um constrangimento na relação dos sujeitos com os objetos (quando os confundem com as mercadorias) e, por consequência, com a memória que estes carregam, justamente por terem sido fetichizados, não há justificativa não fetichizada para a existência de um acervo. Atribuímos vida, memória e sentido, a objetos que, sob outro viés analítico, não podem ter vida. ${ }^{3} \mathrm{O}$ acervo não se engana quanto ao papel fetiche dos objetos.

Um acervo não é nada além daquilo que fazemos dele, só a ação dos sujeitos dá senti-

3 STALLYBRASS, P. $\mathbf{0}$ casaco de Marx: roupas, memória, dor. Tradução de Tomaz Tadeu da Silva. Belo Horizonte: Autêntica, 2004. do aos objetos, e essa relação modifica a qualidade das coisas, o que, numa força inversa, ressignifica os sujeitos. ${ }^{4}$ Por isso nos maravilhamos diante da exposição de uma caneta, de um manuscrito, ou da cadeira de um escritor. 0 mesmo não ocorre com estes objetos quando são apenas mercadorias. 0 fetiche transforma o objeto em algo além de um mero produto. $E$ os acervos são os repositórios desses objetosmemória.

A chave que fecha este dossiê, as escritas de formação, encerra uma discussão muito cara à abordagem (auto)biográfica em educação, que são as escritas produzidas pelos sujeitos em processo de formação. Esses escritos da própria vida e das experiências que nos converteram no que acreditamos que somos, interpelam a pedagogia, como campo de saber que transcende o escolar e que revitaliza seus discursos, saberes e perguntas mediante os vestígios e os documentos autobiográficos dos sujeitos que se formam, ao longo da vida, e em diferentes territórios da experiência social.

A escrita de si, como um recurso à memória e como esforço de biografização, encontra nos processos formativos de estudantes, educadores, trabalhadores, sujeitos em formação permanente, uma possibilidade de acessar as teias complexas que constituem a trama das professoralidades e as dificuldades presentes nas escolhas e hesitações de quem se filia a uma comunidade de práticas e discursos profissionais e, ao mesmo tempo, ganha com isso uma nova posição de sujeito, uma outra identidade. Essas escritas trazem as marcas e as aberturas da memória, como espaço de negociação e invenção de um real, mediado pela escrita, que ativa, mobiliza e se recria no desdobrar do devir do sujeito que escreve e constitui sua identidade mediante uma narrativa.

Além disso, a prática de inscrição e docu-

4 LATOUR, B. Reflexão sobre o culto moderno dos deuses fe(i)tiches. Tradução de Sandra Moreira. Bauru, SP: EDUSC, 2002. 
mentação da própria experiência de formação, o exercício de escrever, o exercício de escrever e reescrever textos autobiográficos, que narrem o processo de sermos os intérpretes de quem somos; a tentativa de colocar no centro de gravidade de um escrito a própria vida e a própria transformação subjetiva, tudo isso supõe uma experiência de formação, um momento de biografização e uma tentativa de reconstrução de si. Talvez, alguns artigos desse dossiê nos permitam uma aproximação dos modos como a pedagogia da formação tem se apropriado destas premissas, como tem reelaborado seus discursos e saberes e projetado dispositivos de pesquisa-formação que se desdobram em torno de escritas de formação.

O texto Autobiografía y Autorretrato, de Luis Porter, procura tensionar os limites entre o biográfico, o ficcional e o teórico, num intricado texto que expõe um olhar sensivel sobre os exercícios ensaísticos da escrita autobiográfica, propondo um diálogo da autobiografia com a poética, o que aproximaria a arte do lugar da investigação, reinserindo-a na pesquisa acadêmica. 0 texto chama a atenção, justamente por ser um ensaio que flerta com a linguagem poética, ao ressaltar como a autobiografia pode funcionar como um mecanismo de diálogo conosco mesmo e com os outros que fizeram parte de nossas vidas.

0 artigo Um acervo autobiográfico: $a$ capoeira dos Mestres Pastinha, Bimba e Cobrinha Verde no Museu Afro-Brasileiro da Universidade Federal da Bahia, de Joseania Miranda de Freitas e Marcelo Nascimento Bernardo da Cunha, apresenta o resultado de uma pesquisa sobre figuras museológicas da cultura da capoeira, na cidade de Salvador. Ao dizer da existência do acervo, os autores prestam um serviço fundamental a coleções dessa natureza, ou seja, ligadas a figuras associadas às culturas marginalizadas brasileiras e de origem africana, num país que, historicamente, invisibilizou
- e perseguiu - os membros dessa manifestação. Utilizando de fontes múltiplas, o trabalho cumpre sua função de lançar luz sobre o material dos autores presentes no Museu Afro-Brasileiro da Universidade Federal da Bahia, bem como nos provoca, através da diversidade de instrumentos, a atacar os acervos, a partir de outros recursos, e não através apenas da pesquisa documental.

O trabalho de Cristina Maria da Silva - A composição de um álbum fotográfico: os rastros de uma avó materna - apresenta uma discussão e ao mesmo tempo um exemplo de como lidar com investigações nas quais os sujeitos da pesquisa possuem alguma proximidade ou parentesco. Apesar dessa dificuldade, que causaria espécie a uma ciência mais ligada ao paradigma positivista, a autora nos conduz pelas suas lembranças, ativadas a partir do álbum de família e da presença de sua avó materna, Tereza. Para ela, "um álbum é pensado como uma construção narrativa e imagética de múltiplas grafias: daqueles que de modo separado realizaram as fotos, as descontinuidades do tempo que as mantiveram separadas, dos conhecimentos, narrativas e sentidos que elas evocam ao olhar, de sua conjugação entre temporalidades". 0 trabalho nos provoca a pensarmos como estes álbuns, estes pequenos acervos familiares, nos permitem acessar uma narrativa que nos leva a reviver uma experiência.

Paloma Nascimento dos Santos e Rochele de Quadros Loquercio, no texto intitulado Ficção para um corpo de cientista: Marie Curie, a invenção de si e a narrativa autobiográfica, abordam a pioneira da ciência e ganhadora do prêmio Nobel, Marie Curie. 0 texto questiona a relação entre as narrativas e as redes de poder articuladas em sua construção, a partir das notas autobiográficas de uma mulher considerada um mito, e problematiza o papel das narrativas na invenção de si, a trajetória au- 
tobiográfica de Curie e a invenção do mito da mãe, esposa e cientista, tendo o gênero como elemento central na construção de uma ficção de mulher nas ciências. Ao lançar luz sobre a trajetória de uma figura pública e consolidada, o artigo evidencia as dificuldades do controle da produção de si e de como estas personas públicas são arrastadas por interpretações e reduções de seus feitos.

O ensaio Por que ele? Reflexões sobre o percurso e os bastidores de uma biografia histórica, de Éder da Silva Silveira, abre um outro leque para a investigação autobiográfica, a pesquisa dos processos de produção de uma investigação. 0 autor propõe-se a lançar um olhar sobre as dificuldades que encontrou na escrita de uma biografia. Dividido em duas partes, na primeira, discute as formas da autobiografia, no âmbito da história. Na segunda, discute algumas possibilidades, inscritas na relação entre o campo autobiográfico e a escrita da micro-história, e defende que a autobiografia, quando produzida por historiadores, pode se ocupar de questões narrativas, contudo sem descuidar das especificidades de uma pesquisa documental.

Em seu texto Escribir, leer y conversar entre docentes en torno de relatos de experiéncias, Daniel Suárez põe em debate as potencialidades metodológicas e políticas de um dispositivo de investigação-formação-ação docente, centrado na documentação narrativa de experiências através da elaboração de relatos autobiográficos. Apresenta-os como uma modalidade do trabalho pedagógico, entre docentes, que promove a participação dos educadores em processos de indagação, desenvolvimento profissional e intervenção político-pedagógica no campo educativo. Na primeira parte, expõe alguns critérios teóricos e metodológicos que informam a documentação narrativa e que entram em diálogo com distintos enfoques de investigação social e educativa: a etnografia da educação, a pesquisa-ação-participativa, a pesquisa-ação docente, os ateliês de investigação da prática. Na segunda parte, descreve o percurso de investigação-formação-ação que professores e pesquisadores realizam, detendo-se nos "momentos" que se passam nesse processo copartícipe, com o objetivo de evidenciar como esses dispositivos metodológicos põem em funcionamento, mobilizam práticas ativas de escrita, leitura, crítica e conversação entre pares, promovendo, então, novas formas de consciência profissional.

Por sua parte, Robson Fonseca Simões, em seu artigo Escritas de si na web: questões para o suporte digital, identifica e problematiza os escritos autobiográficos publicados nas redes sociais escolares, através de uma análise minuciosa de um corpus de "escrituras íntimas", que circulou em uma comunidade virtual da extinta rede social Orkut. Interroga e discute, assim, a questão do tempo na narrativa em meios digitais. Segundo o autor, os internautas publicam suas histórias escolares, no espaço da rede, fazendo com que outras fontes historiográficas tragam e amplifiquem as vozes que clamam por visibilidade e legitimidade, na História da Educação e nas Ciências Humanas. 0 autor conclui, então, que a releitura dessas produções virtuais nos ajuda a refletir sobre o papel que as tecnologias da comunicação e da informação podem desempenhar, como um repositório de documentações autobiográficas.

Lúcia Maria Vaz Peres, Alexandre da Silva Borges e Luciana Martins Teixeira Lindner, em seu artigo A simbólica do batismo capturada em cartas para professores do passado, analisam as narrativas materializadas em cartas solicitadas a estudantes em formação inicial em Pedagogia. 0 texto propõe-se a tomar a escrita epistolar como uma ferramenta empírica para a investigação autobiográfica. Utiliza para isso a análise simbólica, à luz dos estudos teóricometodológicos do imaginário, e dos estudos 
(auto)biográficos de formação, e explora os enfoques e critérios metodológicos da pesquisa-formação.

Em Narrativas de professores e processos de formação: Cuiabá (MT) e São Gonçalo (RJ) em diálogo, Filomena Maria de Arruda Monteiro e Helena da Fontoura colocam em conversação dois projetos complementares de investigação narrativa, desenvolvidos em diferentes instituições de formação de docentes. 0 artigo chama a atenção, especificamente, da questão tanto da investigação narrativa como do entendimento da formação docente como um processo de aprendizagem de estratégias e capacidades, para aprender com os outros, a partir dos outros e para os outros. Conclui-se, portanto, que quando a profissão docente é respeitada e os professores são apoiados, em sua aprendizagem profissional, é provável que aconteça uma melhora na qualidade dos processos educativos, tanto para os professores quanto para os alunos.

Fechando o Dossiê, o artigo As histórias de vida como tramas de fios na composição da professoralidade, de Jussara Midlej e Marcos Villela Pereira, apresenta e discute os critérios teóricos e metodológicos de uma pesquisaformação realizada a partir de uma aproximação (auto)biográfica, entre os anos de 2013 e 2014, em um curso de Pedagogia integrado ao Plano Nacional de Formação de Professores da Educação Básica (PARFOR), em colaboração com a Universidade Estadual do Sudoeste da Bahia (UESB), no campus de Jequié. Segundo os autores, as escritas de si e as ações desenvolvidas nos ateliês desse projeto possibilitaram um plano de recolha de informação, em diferentes circunstâncias e contextos, a fim de ampliar as possibilidades de gerar retorno a partir dos materiais produzidos no processo de formação profissional. Nesse marco, as conversações entre os participantes, em torno dos relatos, são entendidas como ações reciprocas e foram relacionadas com a triangulação formativa e as histórias de vida em contextos de pesquisa e formação. Todas estas ações permitiram aos professores participantes tornar a sua compreensão profissional mais precisa, ao refletirem sobre as experiências e as situações que os docentes vivem nesta região do país.

Com a publicação do terceiro número da Revista Brasileira de Pesquisa (Auto)biográfica concluímos um trabalho colaborativo que tem contribuído para a socialização de estudos e pesquisas, no domínio dos estudos (auto) biográficos, em constante diálogo com pesquisadores brasileiros e estrangeiros que têm se dedicado ao campo de estudo das narrativas, seja como dimensão de pesquisa ou como prática de formação. Desejamos que os textos socializados neste número possam contribuir para a ampliação de pesquisas e práticas de formação que se voltam para os princípios epistemológicos e teórico-metodológicos da pesquisa (auto)biográfica. Assim, desejamos boa leitura nas interfaces com os estudos que se desenvolvem no contexto do movimento biográfico, brasileiro e mundial.

Salvador-Buenos Aires, dezembro de 2016 Daniel Hugo Suárez Universidade de Buenos Aires Rodrigo Matos de Souza Centro Universitário Jorge Amado 